\title{
Effect of an Arabic Program of Direct Instruction for Phonological Awareness on Phonological Awareness Abilities
}

\author{
Hala Elhoweris, Negmeldin Alsheikh, Abdurrahman Al Mekhlafi, \\ Najwa Alhosani, and Mohammed Alzyoudi \\ United Arab Emirates University
}

\begin{abstract}
Reading in Arabic is a vital skill for academic success and progress in the United Arab Emirates (UAE) elementary schools and beyond. However, there is substantial evidence to suggest that a significant number of UAE children in lower elementary grades experience difficulties in reading school-related materials. Research in reading has clearly documented that the lack of phonological awareness skills is a major contributor to reading difficulties. The aims of the present study were to (a) identify phonological awareness deficits among UAE's struggling first-grade readers, (b) provide intervention in the area of phonological awareness deficits through direct training, (c) determine whether phonological awareness direct training significantly increases phonological awareness abilities, and (d) determine the effect of gender on the reading intervention. The results of this study indicate that a direct training intervention program in the UAE positively impacted struggling first-grade readers' phonological awareness abilities.
\end{abstract}

Reading and writing are complex cognitive skills that are predictors of school success. Children who struggle to read and write are at risk of academic failure, behaviour problems, and dropping out of school. Phonological awareness seems to be a panacea for readers who experience reading difficulties, and its efficacy on reading in young learners with reading difficulties is statistically confirmed (Bus \& Van IJzendoorn, 1999; Catts \& Kamhi, 1999; Goswami, 2010; Stanovich \& Siegel, 1994; Swan \& Goswami, 1997; Wagner \& Torgesen, 1987). In a very important sense, the ability of the brain to develop "phonological representations in response to spoken language exposure and learning to speak, and the quality of these phonological representations, determines literacy 
acquisition" (Goswami, 2010, p. 103). Reading is a complex cognitive skill that requires the reader to recognize words and comprehend the text. Beginner readers often struggle to learn how to read because of their inability to recognize and manipulate the sounds of their native language (Stuart, 2005). The lack of phonological awareness skills hinders beginning readers from learning how to decode and spell words effectively (Ryder, Tunmer, \& Greaney, 2008). Leafstedt, Richards, and Gerber (2004) indicated that students with phonological deficits have difficulties understanding words that can be broken into individual phonemes and therefore cannot capitalize on that knowledge.

\section{Phonological Awareness Research}

The significant impact of phonological awareness on the reading ability of young children has been investigated since the 1990s in several countries around the world (e.g., Adams, 1990; Fuchs \& Fuchs, 2006; Torgesen, 1999). Previous studies have documented that there is a strong association between phonological awareness skills and reading and spelling achievement (Center, 2005). Research in the last 20 years strongly supports phonological awareness skills as the predictor of reading success among beginning readers as well as those in later grades (Bernstein \& Ellis, 2000; Goswami, 2002; Goswami, 2010). Indeed, research has demonstrated that phonological awareness is a predictor of reading and spelling success in the early school years (Hogan, Catts, \& Little, 2005). Recently, Abou Elsaad and Abd Elhamed's (2016) study revealed a strong relationship between phonological awareness skills and the proficiency in word reading abilities among Arabic school-aged children. Students identified with reading and/or writing difficulties have a lifetime struggle, and more likely, their academic achievements will be impeded. Therefore, it is imperative to recognize their special needs (Salend, 2008).

Phonological awareness, defined as the awareness of the sound structure of the language, is a critical skill for reading development. It involves identifying and manipulating parts of spoken language such as whole words, syllables, words chunks referred to as onsets and rimes; and phonemic awareness (Virginia Department of Education, 1998). Phonics is the knowledge of the relationship between letters and sounds (Morrow, 2012), so phonemic awareness and phonological awareness are considered precursor to phonics. The Virginia Department of Education (1998, pp. 3-4) suggested five major components for phonological awareness including listening (alertness, sequencing, discrimination, figure-ground, memory, and sound-symbol), rhyme (exposure, judgment, and production), word awareness (pointing and counting), syllable awareness (counting, segmenting, blending, and deletion), and phonemic awareness (initial sound identification and comparison, sound-symbol correspondence, final sound identification, phoneme counting, phoneme segmentation, phoneme blending, phoneme deletion, and phoneme substitution).

In a study that compared phonological awareness abilities between typical Arabspeaking children and Arab children with learning disabilities, Barakah et al. (2015) found that children with learning disabilities scored significantly poorer than typical children in most phonological awareness skills. Indeed, several researchers (e.g., Ammar \& Ridha, 2013) reported that poor readers lack phonemic awareness abilities. According to these researchers, phonemic awareness does not develop spontaneously, 
but only in the specific context of learning to read an alphabetic script at school. Gillon (2000) found that the children with spoken language impairment who received phonological awareness intervention made significantly more gains in their phonological awareness ability and reading development than children receiving other types of interventions. Recently, many researchers reported that integrated phonological awareness intervention programs significantly improved the phonological awareness abilities of students with varying degrees of disabilities (e.g., Gillon \& Macfarlane, 2017; van Bysterveldt, Gillon, \& Foster-Cohen, 2010; van Bysterveldt, Gillon, \& Foster-Cohen, 2014).

According to Rupley, Blair, and Nichols (2009), for students who lack phonological awareness, teachers should use explicit instruction in phonological awareness abilities. Explicit instruction in phonological awareness should be an integral part of learning phonemic awareness, phonics, fluency, vocabulary, and comprehension. Letter-sound relations assist children to read and spell words correctly, whether the words are within or outside of the text (Smith, 2003). Previous researchers indicated that phonological awareness instruction is most effective when provided in small groups of three to five students (e.g., Foorman \& Torgensen, 2001) and whole-class instruction (Center, Freeman, \& Robertson, 2001). Earlier, Griffith (1992) found that children who were taught phonological awareness using whole-language and basal reading approaches outperformed children who were not taught phonological awareness in their reading programs. Torgesen (1999) found reading programs that emphasized even a minimal amount of explicit instruction in phonological awareness succeeded in increasing the proficiency rate of poor readers by $37 \%$.

Research in special education emphasizes the use of small group interventions and one-to-one tutoring in remediating reading difficulties (see Fuchs \& Fuchs, 2006; Salend, 2008). Ryder et al. (2008) found that children in a reading intervention program that emphasized phonological awareness improved their ability to recognize words accurately and to comprehend the reading text. Children who developed phonological awareness skills also learned how to read fluently and accurately at a faster rate (Ehri, 2003). The inclusion of phonological awareness training in discriminating rhyme, alliteration, and phonemic sounds increases reading rate for children with reading difficulties (Smith, 2003). Other studies of phonological awareness programs have shown that they are effective in improving beginning readers' phonological awareness skills (see Aisa, 2007; Al Otaiba et al., 2008; Cardoso-Martins, Mesquita, \& Ehri, 2011). In a review of effective programs for struggling readers, Slavin, Lake, Davis, and Madder (2009) concluded that one-to-one tutoring that focuses on phonics is very effective in improving reading performance.

To summarize, phonological awareness ability is a critical predictor of early reading ability and crucial for subsequent academic success in later stages. Evidence from research overwhelmingly supports phonological awareness training as a precursor for beginning readers to be skillful and fluent readers. 
Studies that have examined the use of phonological awareness programs with struggling readers in the Arab world are rare, most having been carried out in Western countries. However, the findings of these studies provide additional evidence of the need for phonological awareness instruction in overcoming reading difficulties among struggling readers. For example, in a study that investigated the role of phonological awareness in diagnosing developmental dyslexia among Arabic children, Ashor (2010) concluded that phonics training is essential to remediate children with dyslexia. Another study was conducted by Abedlah (2006) to assess the impact of using an intervention program in improving phonological awareness among Arabic beginning readers. The results of this study indicated that the program was effective in facilitating significant improvement in speech production, early reading, and achievement in Arabic language. Layes, Lalonde, and Rebai (2015) examined the effects of a phonological awareness training program on word reading and pseudo-word decoding in children with dyslexia reading Arabic. They found that in comparison to typical readers in Grades 4 and 5, the students with dyslexia performed significantly better in all post-training measurements in reading, phonological processing, and metalinguistic-related skills

\section{UAE Context}

Literacy has been and remains a cornerstone for UAE citizens. In 2015, on the directive of the UAE President, His Highness Sheikh Khalifa bin Zayed Al Nahyan, the UAE cabinet approved the declaration designating 2016 as the UAE Year of Reading. ("UAE Declares," 2015). Although every student in the UAE needs a solid foundation in literacy to be able to enter college, a number of parents and educators have questioned students' reading and writing achievements in English and Arabic languages. There was a virtual national panic about reading and writing achievements in the UAE elementary, secondary, and post-secondary education. Indeed, the consensus is that literacy levels are unsatisfactory at the national level in the UAE. Most children who start off their time in school struggling to learn to read are more likely to be at risk of serious difficulties throughout their time in school. Reading and writing problems can be overcome by early diagnosis and effective instructional strategies that motivates children (Salend, 2008). Therefore, it is imperative to address the literacy problems in the early school years, to avoid negative consequences in subsequent years.

Arabic orthography includes 28 letters, all consonants except for three long vowels: [/a:/],و[/u:/], and ي [/i:/]; short vowels are represented by diacritical dots, making a total of 6 vowels in Arabic. Most Arabic consonants have more than one written form (e.g., /f/ $=$ (ف) depending on whether they occur in the beginning, middle, or end of a word (Ammar \& Ridha, 2013). The Arabic orthographic system is considered phonologically transparent with a high consistent set of phoneme-grapheme correspondences (Abu Rabia, 1999).

Currently, there is scant data on children's phonological awareness skills and the teachers' use of phonological awareness for reading instruction in the UAE. A study by Tibi (2005) indicated that both special and general education teachers in the UAE have limited knowledge of phonological awareness and its application in teaching reading. Additionally, there is substantial evidence to suggest that a significant number of UAE 
children in lower elementary grades experience reading difficulty when approaching school academic materials.

\section{Research Questions}

At the elementary level, success in school is virtually synonymous with success in reading. Because Grade 1 is a critical period for establishing a solid foundation in reading abilities, this study focused on first-grade students with reading difficulties. The intention of this study was to implement a highly effective phonological awareness program based on best practices that could be incorporated into the emergent reading program in lower primary schools in the UAE. Specifically, the research questions of this study are as follows:

1. What phonological awareness skills do UAE's struggling first-grade readers lack?

2. Does an Arabic-language program using direct instruction for phonological awareness significantly improve the phonological awareness abilities of UAE's struggling first-grade readers?

3. Is there any significant gender-based difference in phonological awareness skills among UAE's struggling first-grade readers?

\section{Method}

\section{Participants}

The participants all attended UAE government schools and consisted of 50 struggling first-grade readers: 25 girls and 25 boys ranging in age from five to seven years. For all the participants, Arabic was the mother tongue and the first language. In these schools, Arabic language is assigned for five periods per week. Participants were included in the study using stratified sampling technique and did not differ significantly with respect to pre-test measure in their phonological awareness abilities. They were randomly assigned to either the control or experimental group in their first semester.

These students had been nominated by their teachers as having reading difficulties in Arabic language and as experiencing difficulties in phonological awareness. To verify the source of the participants' difficulty in reading, the participating teachers were asked to use an error analysis sheet (prepared by the researchers) to identify the participants' errors in the reading diagnostic test. Error analysis revealed that all participants had difficulties related to phonological awareness skills.

The two teachers were chosen from two UAE elementary government schools. Both teachers were general education teachers who teach first-grade students. The two Arabic teachers had bachelor's degrees in Arabic teaching and learning, and they were native Arabic speakers.

\section{Instrument}

A quasi-experimental design (pre and post test) was used to answer the research questions of this study. The instrument was developed based on a comprehensive review 
of relevant literature pertaining to phonological awareness assessment and instruction (e.g., Bernstein \& Ellis, 2000; Goswami, 2002; Virginia Department of Education, 1998). The Phonological Abilities Measure (PAM) was used to determine the effects of this study's instruction program (intervention) in improving struggling readers' phonological awareness skills. The PAM consists of 12 phonological awareness skills including the following: sentence segmentation, rhyme recognition, rhyme production, syllable blending, syllable segmentation, syllable deletion, phoneme isolation of initial sounds, phoneme isolation of final sounds, phoneme deletion of initial sounds, phoneme deletion of final sounds, phoneme deletion of first sound in consonant blend, and phoneme substitution. Each skill is assessed by six items, making 72 items in total. The pre-test and post-test measures were not identical, but they both assess the same phonological awareness skills and have the same length.

Validity. To establish content validity of the PAM, four university professors from the field of reading education and special education reviewed each item in the instruments (pre-test and post-test measures). All reviewers indicated that the items of the instruments are appropriate, suitable, and related to phonological awareness skills.

Reliability. Internal consistency was used to measure the reliability of the parallel version of the PAM. More specifically, two versions of the test were developed, a pre-test measure and a post-test measure. The instrument was found to have an alpha coefficient reliability index of .88 for the pre-test measure and of .79 for the post-test measure, which were found to be appropriate for this study.

Intervention. The phonological awareness intervention (direct instruction) program used in this study was supplementary to existing Arabic language and reading instruction, which used indirect or implicit phonological awareness program. The two schools used the Ministry of Education curriculum, which does not include activities that directly or explicitly teach phonological awareness skills. In contrast, our intervention program used best practices for directly or explicitly teaching phonological awareness skills, including teaching strategies such as a multi-sensory approach, flexible grouping, and differentiated instruction (Tomlinson, 2001). The two teachers had received several workshops by the Ministry of Education in using multi-sensory approach and differentiated instruction strategies.

As noted above (see Introduction) Arabic orthography has a consistent letter-sound alphabetical system. Short vowel patterns are rule-governed depending on the meaning of the word, inflections, and the word function in a sentence. In this study all the words used are in voweled form to make it easier for beginner readers to read words or texts.

\section{Intervention Framework}

In this study, a general five-step framework for intervention developed by Gillon (2004) and Gillon and McNeill (2007) was adopted. However, some changes were made to the assessment framework to fit the purpose of the current study. The current study used four-steps including assessment, planning, implementation (intervention), and evaluation. The following paragraphs give a general overview of this four-step framework and the function for each step pertinent to our study. 
1. Assessment: (a) Data on all participants' phonological skills was collected using the pre-intervention measure (PAM), and (b) areas of phonological awareness deficit were identified for the participants.

2. Planning: (a) Participating teachers were trained by the researchers on how to use direct instruction to teach phonological awareness by using flexible grouping, a multisensory approach, and differentiated instruction; and (b) participating teachers were asked to prepare lesson plans (see Appendix) to ensure that they would use similar activities and strategies.

3. Implementation (intervention): (a) Participating teachers were asked to implement the lesson plan as it is, using its activities and strategies within the specified time (similar in length to a typical single class period in the UAE government schools, i.e., 45 minutes); and (b) the two instructions were ensured to be comparable in terms of learning time, teaching strategies, vocabulary, and the targeted phonological awareness skills by reviewing the two teachers' lesson plans, student work samples, and the checklists that the two teachers completed on their own performance.

4. Evaluation: (a) The post-intervention measure (PAM) was administered individually to all participants; and (b) the research team re-evaluated the students' phonological awareness skills.

\section{Procedures}

In spring 2016 the researchers contacted school principals and teachers and requested their participation in this study. Parents of the experimental group of students were contacted, and their agreement was obtained before conducting this study.

Planning. We trained the UAE elementary school teachers who agreed to participate in this study in the special methods of direct instruction for phonological awareness. Upon successful training, the UAE participating teachers carried out the phonological awareness intervention program in autumn 2016.

To control for threats to internal validity, the two groups (experimental and control) of both genders were exposed to the same pre-test measures. Additionally, to avoid design contamination, the two groups (experimental and control) of male and female students were equivalent in terms of age range, phonological awareness ability (both groups scored below average on the pre test), and gender. To minimize crosscontamination of conditions, the participating teachers received instruction related to design contamination and were asked to note anything significant in this regard.

Assessment. To identify phonological awareness deficits, all student participants were individually administered pre-tests of the 12 phonological awareness skills. Each assessment was conducted in a one-on-one (teacher-student) assessment. The teacher communicated directions orally..

Implementation. After identifying the phonological awareness deficits that needed to be taught directly for UAE's struggling beginning readers, we assigned the participants randomly to two groups (A and B) for each gender type, since all government schools in the UAE are same-gender schools. Group A boys (experimental group, $n=12$ ) and 
Group A girls (experimental group, $\mathrm{n}=13$ ) were taught using a program of direct instruction for phonological awareness. Group B boys (control group, $n=13$ ) and Group B girls (control group, $\mathrm{n}=12$ ) were taught using a program of indirect instruction for phonological awareness.

During the 16-week intervention period, the experimental groups were taught by their teachers in a series of special 40-minute classes after school using intensive smallgroup and individualized instruction that included differentiated instruction and a multisensory approach. The class comprised 10 minutes of whole-group instruction, 20 minutes of small-group instruction, and 10 minutes of individualized instruction. It is noteworthy that the phonological awareness training program was designed based on students' needs, providing explicit instruction on the skills that the students were lacking or on their difficulties including segmenting, rhyming, sound blending, and phonemic awareness. Instruction addressed sentence segmenting, rhyming production, syllable segmenting, and phoneme manipulation (e.g., phoneme deletion of initial sounds, phoneme deletion of final sounds, and phoneme substitution). Each lesson introduced, demonstrated, and provided practice sessions in a single phonological awareness skill using drill and practice with multi-sensory and differentiated instruction strategies (see a lesson plan example in the Appendix).

The control groups were taught phonological awareness abilities using implicit or indirect instruction - typical teaching methods in the UAE schools including wholegroup and small-group instruction and a multi-sensory approach.

Evaluation. Following the intervention, all children were given the post-test of phonological awareness. The total score for each skill is six points: Each skill was assessed by six items and each item was worth one point. To determine the mastery level of phonological awareness skills for the whole class, a mean score of $5.4(90 \%)$ was taken to indicate that the participants mastered the phonological awareness skill. A mean score of $4.8(80 \%)$ or higher meant that participants had partially mastered the skill. A mean score of less than 4.8 meant that participants had not mastered the skill. Thus, the skill was considered as an area of deficit or difficulty if the mean scores fell below 4.8 or $\leq 79 \%$.

\section{Data Analysis}

Descriptive statistics such as frequencies and percentages were used to analyze quantitative data such as students' scores in phonological awareness skills. To measure the impact of the instruction program on the phonological awareness skills of UAE's struggling first-grade readers, an independent sample $t$-test was used.

\section{Results}

To answer research question 1, "What phonological awareness skills do UAE's struggling first-grade readers lack?", all the participants (experimental and control groups) were given pre-assessments to identify their common areas of phonological awareness deficits. The results of the pre-test measurement revealed that there are no statistically significant differences between Group A and Group B in phonological 
awareness abilities ( $p \geq .05)$, indicating that the two groups lacked the phonological awareness skills that have been assessed in this study.

Based on the pre-test scores, the participants had difficulties in segmenting, rhyming, sound blending, and phonemic awareness. The participating teachers provided direct and explicit instruction in six phonological awareness skills as shown in Table 1.

The results of the pre test indicated that prior to the intervention, participants had mastered only two phonological awareness skills, namely phoneme isolation of initial sounds and phoneme isolation of final sounds (see Table 1); that is, the isolation of a phoneme was an easy task for the participants of this study. Therefore, the intervention training program did not target these two skills. To ensure that all participants mastered these skills, participating teachers reviewed the pre-test assessment for each individual student, and they reviewed samples of the students' work and students' previous performances at these phonological awareness skills.

Table 1

\section{Pre-test Phonological Awareness Skills Assessment Results} for First-grade Struggling Readers

\begin{tabular}{lcc} 
Category & Mean & \% \\
\hline Concept of Spoken Word (Sentence Segmentation) & 3.2 & 53.3 \\
Rhyme Recognition & 3.6 & 60.0 \\
Rhyme Production & 1.9 & 31.7 \\
Syllable Blending & 4.1 & 68.3 \\
Syllable Segmentation & 2.4 & 40.0 \\
Syllable Deletion & 4.6 & 76.7 \\
Phoneme Isolation of Initial Sounds & 5.9 & 98.3 \\
Phoneme Isolation of Final Sounds & 5.4 & 90.0 \\
Phoneme Deletion of Initial Sounds & 3.0 & 50.0 \\
Phoneme Deletion of Final Sounds & 3.6 & 60.0 \\
Phoneme Deletion of First Sound in Consonant Blend & 3.5 & 58.3 \\
Phoneme Substitution & 2.9 & 48.3 \\
\hline
\end{tabular}

Question 2 asks, "Does an Arabic-language program using direct instruction for phonological awareness significantly improve the phonological awareness abilities of UAE's struggling first-grade readers?" The results the post test as reported in Table 2 reveal significant differences between Group A (experimental) and Group B (control). Students in Group A experienced greater improvements than students in Group B.

To answer question 3, "Is there any significant gender-based difference in phonological awareness skills among UAE's struggling first-grade readers?", boys' and girls' post-test scores were compared using the $t$-test. Results of the analysis indicated that there were no statistically significant differences in the PAM overall scores of boys and girls at $p .05$ level, $t=1.33$. So, there is no statistically significant effect of gender on phonological awareness skills. 
Table 2

\section{Differences in Post-test Mean Scores of Phonological Awareness} Between Group $A$ and Group B

\begin{tabular}{lccc}
\hline \multicolumn{1}{c}{ Category } & $\begin{array}{c}\text { Group A } \\
\text { Mean }\end{array}$ & $\begin{array}{c}\text { Group B } \\
\text { Mean }\end{array}$ & t \\
\hline Concept of Spoken Word (Sentence Segmentation) & 5.2 & 2.6 & $2.2^{*}$ \\
Rhyme Recognition & 5.0 & 3.3 & $2.4^{*}$ \\
Rhyme Production & 2.7 & 1.7 & 0.9 \\
Syllable Blending & 6.0 & 2.9 & $4.9^{* *}$ \\
Syllable Segmentation & 4.7 & 1.1 & $4.4^{* *}$ \\
Syllable Deletion & 6.0 & 4.0 & $3.3^{*}$ \\
Phoneme Isolation of Initial Sounds & 5.8 & 1.9 & $4.2^{* *}$ \\
Phoneme Isolation of Final Sounds & 6.0 & 3.5 & $3.1^{*}$ \\
Phoneme Deletion of Initial Sounds & 4.8 & 2.6 & 2.0 \\
Phoneme Deletion of Final Sounds & 4.3 & 3.1 & 1.0 \\
Phoneme Deletion of First Sound in Consonant Blend & 4.7 & 2.6 & 1.7 \\
Phoneme Substitution & 4.2 & 2.9 & 1.3 \\
\hline Total & 4.9 & 2.7 & $5.4^{* *}$ \\
\hline
\end{tabular}

Note. ${ }^{*} p$-value significant at .05 and ${ }^{* *} p$-value significant at .01

\section{Discussion}

Results of this study indicate that the program of direct instruction for phonological awareness did produce slight improvements in UAE's struggling first-grade learners' ability in word segmentation. This result supports previous studies that indicated that phonological awareness direct instruction training program leads to improvements in students' reading abilities and phonological awareness abilities (e.g., Abou Elsaad \& Abd Elhamed, 2016; Layes, Lalonde, \& Rebai, 2015; Smith, 2003).

Results of this study further indicate that the direct and explicit instruction in phonological awareness using flexible grouping format (e.g., whole class, small groups, and one-to-one tutoring) positively impacted UAE first graders with reading difficulties. This confirms findings of previous researchers who indicated that phonological awareness instruction is most effective when provided directly through one-to-one tutoring (2009), small groups (Foorman \& Torgensen, 2010), and whole classes (Center et al., 2001). Our findings support previous recommendations that teachers should use explicit instruction in phonological awareness in teaching students who lack phonological awareness (e.g., Algozzine, 2008) and that teachers should target and train students in the phonological awareness skills directly and explicitly. The importance of direct instruction is highlighted by our finding that the improvements among UAE's struggling first-grade readers vary from one skill to another.

In our UAE-based study of struggling first-grade readers, we found no statistically significant effect of gender in the effects of direct instruction on phonological awareness 
skills. This finding is consistent with Musa and Balami's (2016) study, which investigated the impact of sex on reading performance in children with dyslexia. Using phonological awareness skill training, they found no significant effect of sex on the effectiveness of the intervention.

\section{Implications}

This research provides a solid framework for phonological awareness instruction based on scientific research that can substantially improve the reading skills of UAE beginning readers. Teaching Arabic in many UAE elementary schools is currently based on the whole-word approach, which uses a program of indirect or implicit phonological awareness instruction. However, given that in the current study direct phonological awareness instruction outperformed an indirect approach in addressing the reading difficulties of UAE first graders with poor phonological awareness, it might be more effective if teachers' education programs prepared pre-service teachers to teach phonological awareness explicitly to beginner readers.

Certainly, since phonological awareness is a precursor for reading acquisition and has consequences for reading proficiency in later years, the Ministry of Education in the UAE and the Abu Dhabi Education Council should train in-service teachers to identify children who have difficulties in phonological awareness. Further, they should (a) ensure that elementary school teachers are aware of the positive impact of direct instruction program as a viable means for improving phonological awareness skills among students with reading difficulties in first grade, and (b) teach them how to provide direct phonological awareness instruction using flexible grouping, multi-sensory approach, and differentiated instruction.

Within their classrooms, UAE elementary school teachers need to consider using a direct phonics approach with beginner readers. We encourage those teaching Arabic language to be cognizant of phonological awareness and to employ a balanced approach between whole language and phonics, in which phonics can be taught directly and in a meaningful context.

Regarding implications for future research, it will be important to examine the longterm effect of this or similar intervention programs on phonological awareness, and to measure the impact on reading performance and comprehension skills.

\section{Limitations}

Since the age range (5-7 years old) of the participants appears quite small, future researchers may need to consider the use of ANCOVA and including age as a covariate.

\section{References}

Abedlah, A. (2006, February). The impact of using intervention program in improving phonological awareness for pre-school students. Paper presented at the 3rd Conference of Social Sciences Faculty, Kuwait.

Abou-Elsaad, T., \& Abd Elhamid, H. (2016). Assessment of Arabic phonological awareness and its relation to word reading ability. Logopedics Phoniatrics Vocology, 41(4), 174-80. doi:10.3109/1401-5439.2015 
Abu Rabia, S. (1999). The effect of Arabic vowels on the reading comprehension of second- and sixth grade native Arab children. Journal of Psycholinguistic Research, 28(1), 93-101.

Adams, M. J. (1990). Beginning to read: Thinking and learning about print. Cambridge, MA: MIT Press.

Aisa, A. (2007). The impact of using phonological program on improving reading skills for students with reading difficulties in English language. Education College Journal 72, 95-124.

Al Otaiba, S., Connor, C., Lane H., Kosanovich, M., Schatschneider, C., Dyrlund A., Miller, M., Wright, T. (2008). Reading First kindergarten classroom instruction and students' growth in phonological awareness and letter naming-decoding fluency. Journal of School Psychology, 46, 281-314. doi:10.1016/j.jsp.2007.06.002

Ammar, M., \& Ridha, M. (2013). The role of Arabic orthographic literacy in the phonological awareness of Tunisian children. The African Symposium, 13(1), 19-27.

Ashor, A. (2010). The phonological awareness and its role in diagnosis and treating children with dyslexia. Arabic Journal for Learning Disabilities, 1(1), 66-78.

Barakah, M. S., Elshobary, A. M., El-Assal, N. N., Habil, I. S., Eldin, S. K., El-Refaie, D. A. (2015). Phonological awareness deficits in Arabic-speaking children with learning disabilities. Egyptian Journal of Otolaryngology, 31(2), 140-142.

Bernstein, L., \& Ellis, N. (2000). There are three sounds in the word CAT: How phonemic awareness works to facilitate reading acquisition. Retrieved from ERIC database (ED448408).

Bus, A. G., \& Van IJzendoorn, M. H. (1999). Phonological awareness and early reading: A metaanalysis of experimental training studies. Journal of Educational Psychology, 91(3), 403-414.

Cardoso-Martins, C., Mesquita, T. C., \& Ehri, L. (2011). Letter names and phonological awareness help children to learn letter-sound relations. Journal of Experimental Child Psychology, 109, 25-38. doi:10.1080/0300-4430.2012.703183.

Catts, H. W., \& Kamhi, A. G. (Eds.). 1999. Language and reading disabilities. Boston, MA: Allyn and Bacon.

Center, Y. (2005). Beginning reading: A balanced approach to literacy instruction during the first three years at school. Crows Nest, Australia: Allen \& Irwin.

Center, Y., Freeman, G., \& Robertson, G. (2001). The relative effect of a code-oriented and a meaning-oriented early literacy program on regular and low progress Australian students in year 1 classrooms which implement Reading Recovery. International Journal of Disability, Development and Education, 48(2), 207-232.

Ehri, L. C. (2003). Systematic phonics instruction: Findings of the National Reading Panel. Retrieved from ERIC database (ED479646).

Gillon, G. (2000). The efficacy of phonological awareness intervention for children with spoken language impairment. Language, Speech, and Hearing Services in Schools, 31(2), 126-141. doi:10.1044/0161-1461.3102.126.

Gillon, G. (2004). Phonological awareness: From research to practice. New York, NY: Guilford Press.

Gillon, G., \& Macfarlane, H. (2017) A culturally responsive framework for enhancing phonological awareness development in children with speech and language impairment. Speech, Language and Hearing, 20(3), 163-173.

Gillon, G. T., \& McNeill, B. C. (2007). Integrated phonological awareness: An intervention program for preschool children with speech-language impairment. Christchurch, New Zealand: Author. Retrieved from https://www.researchgate.net/publication/283582997_Gillon_and _McNeill_2007_Integrated_Phonological_Awareness_An_intervention_program_for_presch ool_children_with_speech_impairment 
Goswami, U. (2002). Phonology, reading development, and dyslexia: A cross-linguistic perspective. Annals of Dyslexia, 52, 141-163.

Goswami, U. (2010). Phonology, reading and reading difficulty. In K. Hall, U. Goswami, C. Harrison, S. Ellis, \& J. Soler (Eds.), Interdisciplinary perspectives on learning to read: Culture, cognition and pedagogy. London, UK: Routledge.

Griffith, P. (1992). The effect of phonemic awareness on the literacy development of first-grade children in a traditional or whole language classroom. Journal of Research in Childhood Education, 6(2), 85-92. doi:10.1080/02568-549209594825

Hogan, T., Catts, H., \& Little, T. (2005). The relationship between phonological awareness and reading: Implications for the assessment of phonological awareness. Language, Speech, and Hearing Services in Schools, 36, 285-293.

Layes, S., Lalonde, R., \& Rebai, M. (2015). Effectiveness of a phonological awareness training for Arabic disabled reading children: Insights on metalinguistic benefits. Bellaterra Journal of Teaching \& Learning Language \& Literature, 8(4), 24-42.

Leafstedt, J. M., Richards, C. R., \& Gerber, M. M. (2004). Effectiveness of explicitphonologicalawareness instruction for at-risk English learners. Learning Disabilities Research \& Practice, 19(4), 252-261.

Morrow, L. M. (2012). Literacy development in the early years: Helping children read and write (7th ed.). Boston, MA: Pearson Production.

Rupley, W. H., Blair, T. R., \& Nichols, W. D. (2009), Effective reading instruction for struggling readers: The role of direct/explicit teaching. Reading \& Writing Quarterly, 25(2-3), 125-138. doi.org/10.1080/10573560802683523

Ryder, J. F., Tunmer, W. E., \& Greaney, K. T. (2008). Explicit instruction in phonemic awareness and phonemically based decoding skills as an intervention strategy for struggling readers in whole language classrooms. Reading and Writing, 21, 349-369.

Salend, S. (2008). Creating inclusive classroom: Effective and reflective practices for all learners. Upper Saddle River, NJ: Prentice Hall.

Slavin, R. E., Lake, C., Davis, S., \& Madden, N. (2009). Effective programs for struggling readers: A best-evidence synthesis. Retrieved online from Best Evidence Encyclopedia, www.bestevidence.org

Smith, C. B. (2003). Phonological awareness: ERIC topical bibliography and commentary. Retrieved from ERIC database (ED 480635).

Stanovich, K. E., \& Siegel, L. S. (1994). Phenotypic performance profile of children with reading disabilities: A regression-based test of the phonological-core variable-difference model. Journal of Educational Psychology, 86, 24-53.

Stuart, M. (2005). Phonemic analysis and reading development: Some current issues. Journal of Research in Reading, 28(1), 39-49.

Swan D., Goswami U. (1997). Phonological awareness deficits in developmental dyslexia and the phonological representations hypothesis. Journal of Exceptional Child Psychology, 66(1), $18-41$.

Tibi, S. (2005). Teachers' knowledge and skills in phonological awareness in United Arab Emirates. International Journal of Special Education, 20(1), 60-66.

Tomlinson, C. A. (2001). How to differentiate instruction in mixed ability classrooms (2nd ed.). Alexandria, VA: Association for Supervision and Curriculum Development. 
Torgesen, J. K. (1999). Assessment and instruction for phonemic awareness and word recognition skills. In H. W. Catts \& A. G. Kamhi (Eds.), Language and reading disabilities (pp. 128153). Boston, MA: Allyn and Bacon.

UAE declares 2016 as Year of Reading. (2015, December 5). Gulf News. Retrieved from http://gulfnews.com/news/uae/government/uae-declares-2016-as-year-of-reading-1.1631695

Van Bysterveldt, A, Gillon, G., \& Foster-Cohen, S. (2010) Integrated speech and phonological awareness intervention for pre-school children with Down syndrome. International Journal of Language \& Communication Disorders, 45(3), 320-335.

Van Bysterveldt, A, Gillon, G., \& Foster-Cohen, S. (2014) A phonological awareness intervention case study of a child with Down syndrome. Speech, Language and Hearing, 17(1), 25-36.

Virginia Department of Education. (1998). Ideas and activities for developing phonological awareness skills: A teacher resource supplement to the Virginia early intervention reading initiative. Richmond, VA: Author. Retrieved from https://melrosecurriculum.wikispaces.com /file/view/Phonological+Awareness+Activities.pdf

Wagner, R. K., \& Torgesen, J. K. (1987). The nature of phonological processing and its causal role in the acquisition of reading skills. Psychological Bulletin, 101(2), 192-212.

\section{Authors' Note}

Correspondence concerning this article should be addressed to Dr. Hala Elhoweris, Faculty of Education, Special Education Department, UAE University, P.O. Box 17551, United Arab Emirates. Email: halae@uaeu.ac.ae 


\section{Appendix}

\section{Example of Lesson Plan}

\section{Learning Outcomes}

- Students will be able to identify Arabic rhyming words

\section{Introduction (5 minutes)}

1. The teacher introduces the concept of rhyming words to students in Arabic. Explain that rhyming words are words that have the same ending sounds. For example, "مات" [mæt] and "فات" [fæt] are Arabic rhyming words.

2. The teacher reads aloud a rhyming poem, emphasize the rhyming words, and ask students to listen for rhymes in the poem.

3. After each rhyme, ask students to clap and then tell what rhyming words they noticed.

\section{Explicit Instruction/Teacher Modeling (20 minutes)}

1. Read aloud a rhyming story and emphasize rhyming words.

2. Pause occasionally and ask students in pairs to point out which words rhyme and discuss why they rhyme and then share their response with the teacher.

3. Explain directly to students how some Arabic words sound the same at the end (at) $($ ) $[-æ t]$

\section{Guided Practice (10 minutes)}

1. Divide the class into groups (3-4students per group).

2. Hand each group mixed flashcard sets of rhyming words.

3. Ask students to look through the cards and pairing up rhyming words.

4. Distribute different worksheets to each group according to the students' abilities (differentiation). For example, high achievers can be asked to go over a story book and identify rhyming words as much as they can. And low achievers can go over different pairs of rhyming words using one-on-one approach.

\section{Assessment (10 minutes)}

1. Ask each student to write down three pairs of rhyming words on the given sheet.

2. High achievers can be given an extra assignment to create a "who am I" poem including rhyming words. 